\title{
Drought tolerance and yield increase of soybean resulting from improved symbiotic $\mathrm{N}_{2}$ fixation
}

\author{
Thomas R. Sinclair ${ }^{\mathrm{a}, *}$, Larry C. Purcell ${ }^{\mathrm{b}}$, C. Andy King ${ }^{\mathrm{b}}$, Clay H. Sneller ${ }^{\mathrm{c}}$, \\ Pengyin Chen ${ }^{\mathrm{b}}$, Vincent Vadez ${ }^{\mathrm{d}}$ \\ ${ }^{a}$ Agronomy Department, University of Florida, Gainesville, FL 32611-0965, USA \\ ${ }^{\mathrm{b}}$ Department of Crop, Soil, and Environmental Sciences, University Arkansas, Fayetteville, AR 72701, USA \\ ${ }^{\mathrm{c}}$ Horticulture and Crop Science, Ohio State University, 1680 Madison Avenue, Wooster, OH 44691, USA \\ ${ }^{\mathrm{d}}$ International Crops Research Institute for the Semi-Arid Tropics, Patancheru 502 324, Andhra Pradesh, India \\ Received 2 August 2006; received in revised form 20 September 2006; accepted 21 September 2006
}

\begin{abstract}
Drought is by far the most important environmental factor contributing to crop yield loss, especially in soybean [Glycine max (L.) Merr.] where symbiotic fixation of atmospheric nitrogen $\left(\mathrm{N}_{2}\right)$ is sensitive to even modest soil water deficits. Decline of $\mathrm{N}_{2}$ fixation with soil drying causes yield reductions due to inadequate $\mathrm{N}$ for protein production, which is the critical seed product. In this paper, we present a combined physiological and breeding research effort to develop soybean lines that have diminished sensitivity of $\mathrm{N}_{2}$ fixation to drought. A preliminary physiological screen was used to identify lines that potentially expressed $\mathrm{N}_{2}$ fixation drought tolerance. One hundred progeny lines derived from a cross between Jackson, a cultivar proven to have $\mathrm{N}_{2}$ fixation tolerance to drought, and KS4895, a high-yielding line, were tested in the screen. Seventeen lines were identified for subsequent yield trials in moderate- and low-yielding rainfed environments. Two lines, found to have higher yields than commercial checks in these environments were then tested in the greenhouse for their $\mathrm{N}_{2}$ fixation activity in drying soil. Nitrogen fixation activity was found to persist at lower soil water contents than exhibited by the sensitive parent. These two soybean lines offer a genetic resource for increased yields under rainfed conditions as a result of decreased sensitivity of $\mathrm{N}_{2}$ fixation to water deficit.
\end{abstract}

(C) 2006 Elsevier B.V. All rights reserved.

Keywords: Drought; Nitrogen fixation; Soybean; Yield increase

\section{Introduction}

Drought is the major limitation of crop yields world wide (Boyer, 1982). In soybean, drought not only results in losses in $\mathrm{CO}_{2}$ accumulation and leaf area development but its symbiotic $\mathrm{N}_{2}$ fixation is especially vulnerable to drought (Sinclair and Serraj, 1995; Serraj et al., 1999a). With declining soil water content, soybean has decreased $\mathrm{N}_{2}$ fixation rates in advance of declines of other physiological processes (Sinclair, 1986; Sall and Sinclair, 1991; Serraj and Sinclair, 1997). This means a decrease in $\mathrm{N}$ availability to support cell and tissue development throughout the plant.

The extent of yield reduction resulting from drought associated with diminished $\mathrm{N}_{2}$ fixation activity can be inferred from field studies in which $\mathrm{N}$ fertilizer was applied to water-

\footnotetext{
* Corresponding author. Tel.: +1 352392 6180; fax: +1 3523926139 .

E-mail address: trsincl@ifas.ful.edu (T.R. Sinclair).
}

deficit plots. This treatment, which eliminated crop dependence on $\mathrm{N}_{2}$ fixation, resulted in $15-20 \%$ greater yields than those plots dependent on $\mathrm{N}_{2}$ fixation (Purcell and King, 1996; Ray et al., 2006). The yield advantage of $\mathrm{N}$ fertilization was observed in treatments producing yields up to $350 \mathrm{~g} \mathrm{~m}^{-2}$.

The basis for the sensitivity of soybean to soil drying has been shown to be associated with transport of $\mathrm{N}$ as ureides from nodules to the shoot. Those species that transport $\mathrm{N}$ as amides have $\mathrm{N}_{2}$ fixation that is much less sensitive to soil drying than those that transport ureides (Sinclair and Serraj, 1995). Soybean accumulates uriedes during soil drying, affecting $\mathrm{N}_{2}$ fixation activity (deSilva et al., 1996; Serraj and Sinclair, 1996a; Serraj et al., 1999b). It has been demonstrated directly in feeding experiments that soybean plants fed ureides have substantially decreased $\mathrm{N}_{2}$ fixation rates (Vadez et al., 2000).

A genetic exception to early decline in $\mathrm{N}_{2}$ fixation by soybean during soil drying was found in the obsolete and lowyielding cultivar Jackson (released in 1953). The decline in $\mathrm{N}_{2}$ 
fixation rate in Jackson with soil drying occurred at lower soil water contents than observed in other tested cultivars (Sall and Sinclair, 1991; Serraj and Sinclair, 1997). The advantage of Jackson at the physiological level was shown to be associated with its ability to minimize the accumulation of ureides throughout the plant under drought stress (Serraj and Sinclair, 1996a, 1997). Jackson is able to rapidly metabolize ureides in the leaf and this appears to be associated with an ability to readily accumulate manganese (Vadez and Sinclair, 2002).

While there is frequent speculation about improving crop performance by alteration of physiological traits, successes based on this fundamental assumption have proven elusive. Nevertheless, a long-term, multi-disciplinary research program was begun to produce high-yielding lines for non-irrigated conditions that exploited the $\mathrm{N}_{2}$ fixation drought tolerance (NFDT) trait of Jackson. There were four phases to this research: (1) Jackson was mated with high-yielding cultivars, (2) a preliminary physiological screen was used to identify progeny lines with potentially high NFDT under water deficit, (3) field trials were undertaken to identify genotypes with superior yields in water-limited environments, and (4) a greenhouse experiment was done to verify NFDT in the highyielding lines.

\section{Materials and methods}

Jackson was hybridized with several high-yielding cultivars in 1993, but ultimately, the cross of greatest promise was Jackson $\times$ KS4895. KS4895 is a widely adapted, high-yielding cultivar, which has proved valuable as a parent in developing lines with superior yields. However, KS4895 does not possess NFDT (Purcell et al., 1997, 2000). The plant population derived from Jackson $\times$ KS4895 was advanced to the $\mathrm{F}_{3}$ stage by single seed decent.

All lines were grown in the field and evaluated for maturity date and the robustness of the plants. There was a wide range in maturity group among the tested progeny lines resulting from the difference in maturity between the two parental lines (maturity group 6 versus 4 ). One hundred $\mathrm{F}_{3: 4}$ lines of similar maturity (maturity group 5) were chosen for preliminary evaluation of potential NFDT.

\subsection{Initial greenhouse screen}

An initial greenhouse test was done to identify those lines that potentially expressed NFDT. Each line was grown in eight replicate pots $(1.9 \mathrm{~L})$ filled with an $\mathrm{N}$-free peat-perlite mixture. The potting mixture was inoculated with Bradyrhizobium japonicum USDA 110 and all plants were well nodulated. Pots were fully watered until the plants had approximately six leaves and then half the pots of each line were allowed to dry. A moderate drought stress was established in the dry pots so that daily transpiration was approximately $50-60 \%$ of the wellwatered pots (fraction transpirable soil water $=0.15-0.18$ ). All pots were weighed daily, and watered to return the soil water content in each pot to either the well-watered or the desired drought-stress level. At the end of a 2-week drought, all plants were harvested and measured for $\mathrm{N}$ concentration using a combustion method (Leco FP-428 Determinator, Leco Corp., St. Joseph, MO). Potential NFDT was assessed by the amount of $\mathrm{N}$ accumulated in the shoots of the drought-stressed plants. Those lines with high amounts of $\mathrm{N}$ in the plants from the drought-stressed treatment were identified as potentially having greater $\mathrm{N}_{2}$ activity under water-deficit conditions than the other tested lines.

\subsection{Field yield assessment}

Seventeen lines selected in the greenhouse study were evaluated in field yield trials conducted over 7 years and 6 diverse locations, including sites in Arkansas, Florida, and North Carolina. Two or three high-yielding commercial cultivars (Hutcheson, Ozark, Dillon) of similar maturity to the progeny lines served as checks in each environment. Plots in nearly every case were in a randomized complete block design with three replications. Recommended agronomic practices were used on all plots in regards to fertilization (no $\mathrm{N}$ fertilization) and pest control. Nearly all environments included both a non-irrigated treatment and a treatment with some level of irrigation.

Seed yields were determined from the two center rows from the 4-row plots (4.9-m long and 0.76-m row spacing). Yields of the progeny lines were compared to the mean of the commercial checks, by calculating differences in average yield between each progeny lines and the mean of the checks.

\subsection{Greenhouse verification of $N_{2}$ fixation drought tolerance}

Nitrogen fixation activity of genotypes was measured on plants grown in a greenhouse in 1.4-L pots. Eight pots of each genotype were kept well-watered until six leaves had emerged, and then a dry-down treatment was initiated in five of the pots while three pots were maintained well-watered. Drying pots were weighed daily, and water was added if necessary to limit the net daily decrease in soil water content to approximately $70 \mathrm{~g}$ per pot. This regime allowed the drying of the soil to occur over a 2-week period.

A flow-through acetylene reduction assay was performed each day for each pot during the drying treatment to monitor $\mathrm{N}_{2}$ fixation activity (Sall and Sinclair, 1991; Serraj and Sinclair, 1996b). A 1:9 mixture of acetylene:air was flowed continuously through the pots for $15 \mathrm{~min}$ each afternoon. The gas mixture leaving the pot was sampled and the ethylene concentration measured to estimate $\mathrm{N}_{2}$ fixation activity. After collecting the gas samples, the pots were flushed solely with air for a further $2 \mathrm{~h}$. On each day of the experiment, a $\mathrm{N}_{2}$ fixation ratio was calculated by dividing ethylene production in each of the five drying pots by the mean activity of the three well-watered plants. The individual ratios were plotted against the relative amount of water in the soil expressed as the fraction of transpirable soil water. These data were the basis for establishing the sensitivity of $\mathrm{N}_{2}$ fixation of each genotype to drying soil. 


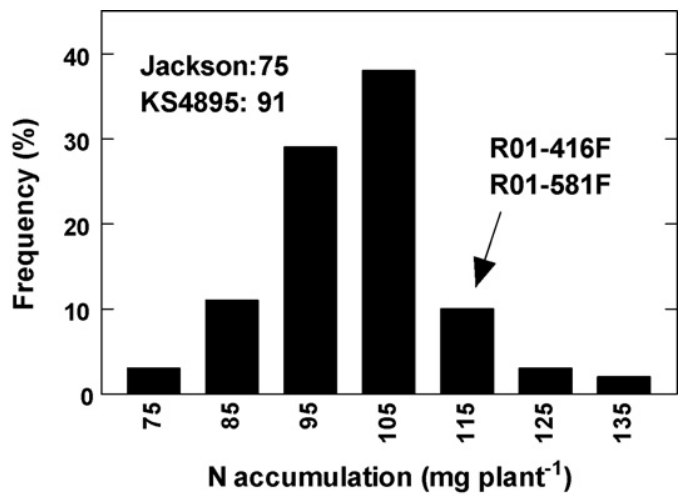

Fig. 1. Distribution in amount of shoot $\mathrm{N}$ accumulated under drought conditions among $100 \mathrm{~F}_{3: 4}$ progeny lines, derived from Jackson $\times \mathrm{KS} 4895$ mating. Included in the histogram is the $\mathrm{N}$ accumulated by each of the parents.

\section{Results and discussion}

The preliminary screen in the greenhouse of $\mathrm{N}$ accumulation under water-deficit showed considerable variability among lines with a number of lines having $\mathrm{N}$ accumulation greater than either parent (Fig. 1). The poor performance of each of the parents was probably a result of different weaknesses. Jackson is not a very robust line and the poor $\mathrm{N}$ accumulation under drought in this experiment reflected its poor growth; KS4895 is a high-growth line, in which $\mathrm{N}_{2}$ fixation is vulnerable to drought. The high number of progeny that accumulated more $\mathrm{N}$ than either parent seems to indicate that they expressed to different extents a favorable combination of robust growth and NFDT. Seventeen lines with high $\mathrm{N}$ accumulation were selected based on this physiological screen for evaluation of yield performance in extensive field trials.

Results of the field trials showed that most progeny lines failed to have yields competitive with the commercial check lines. Two progeny lines, however, demonstrated superior yields as compared to the commercial checks in moderate to low yielding environments, i.e. water-limited situations. Line R01-416F achieved yields greater than or equal to the commercial checks in all except one of the eleven lowest yielding environments (Fig. 2). In environments where yield of

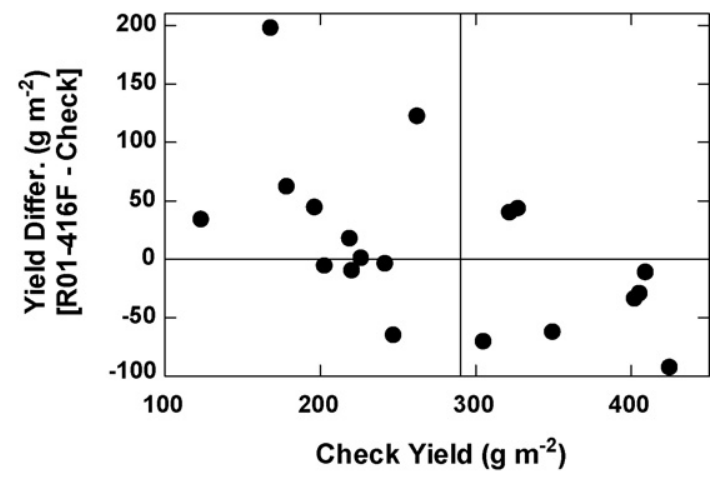

Fig. 2. Difference in yield between R01-416F and the average of the commercial checks plotted against the yield of the commercial checks in each of the tested environments. The vertical dashed line is drawn at a yield of $290 \mathrm{~g} \mathrm{~m}^{-2}$ for the commercial checks. the commercial checks was less than $300 \mathrm{~g} \mathrm{~m}^{-2}$, the average yield of R01-416F was $17.1 \%$ greater $(p=0.065)$. At least part of the basis for this yield gain would seemingly have been a result of NFDT. The yield gain achieved by R01-416F was fully consistent with field experiments (Purcell and King, 1996; Ray et al., 2006) in which dependence on $\mathrm{N}_{2}$ fixation was removed by fertilizing soybean with high levels of N. For example, in the experiments of Ray et al. (2006) non-irrigated, N-fertilized plots out yielded the $\mathrm{N}_{2}$ fixation dependent plots by $15.5 \%$ for the range of yields $<350 \mathrm{~g} \mathrm{~m}^{-2}$.

The yield advantage of R01-416F did not extend to highyield levels $\left(>350 \mathrm{~g} \mathrm{~m}^{-2}\right.$ ) where water was not limiting and R01-416F had yields consistently lower than the commercial checks (Fig. 2). This raises the concern that the NFDT may impose some yield 'drag' in high-yield environments. There is no obvious physiological reason that NFDT would depress yields in high-yield environments. It may be that R01-416F is not fully adapted to high-yield environments.

The above conclusion is supported to some extent by the yield response of R01-581F. This genotype did not show a yield inhibition as compared to commercial checks when yields were greater than $360 \mathrm{~g} \mathrm{~m}^{-2}$ (Fig. 3). Importantly, R01-581F showed a yield advantage in the moderate yield range of $250-360 \mathrm{~g} \mathrm{~m}^{-2}$ where in all eight environments $\mathrm{R} 01-581 \mathrm{~F}$ had yields equal to or greater than the commercial checks. The average yield advantage of $\mathrm{R} 01-581 \mathrm{~F}$ in this range was $33.0 \mathrm{~g} \mathrm{~m}^{-2}$, or $10.7 \%$ greater than the commercial checks $(p=0.009)$.

Combined, the yield results for the two progeny lines of Jackson $\times$ KS 4895 showed a yield advantage in environments where the yields were moderately depressed yields by limited water availability. Yield benefits would be consistent with a NFDT trait. The greatest yield benefits from NFDT could be expected under conditions where there are moderate soil water deficits. Very severe droughts would result in very low $\mathrm{N}_{2}$ fixation rates even with the NFDT trait so there would be little basis for yield gain. Nevertheless, the yield of R01-581F across all 29 environments in which this line was tested was $7.8 \mathrm{~g} \mathrm{~m}^{-2}$ greater than the commercial checks $(p=0.147)$.

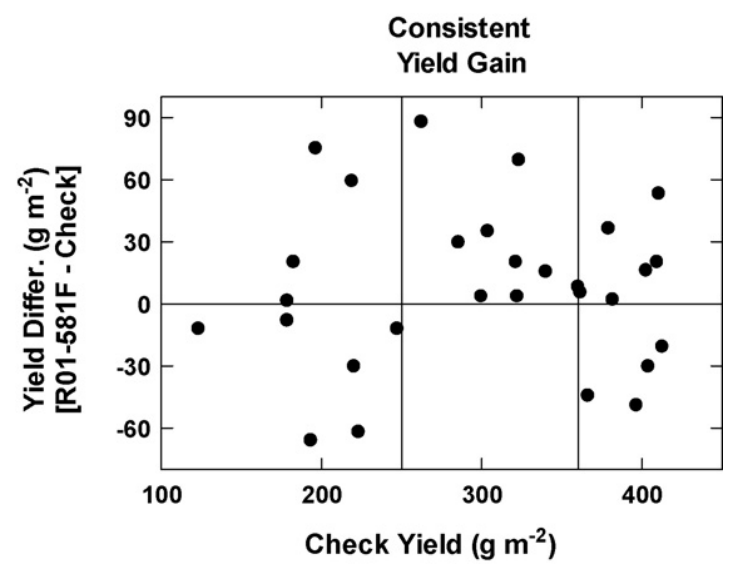

Fig. 3. Difference in yield between R01-518F and the average of the commercial checks plotted against the yield of the commercial checks in each of the tested environments. The vertical dashed lines are drawn at yields of 250 and $360 \mathrm{~g} \mathrm{~m}^{-2}$ for the commercial checks to delineate the mid range where R01$581 \mathrm{~F}$ consistently had greater yields than the commercial checks. 


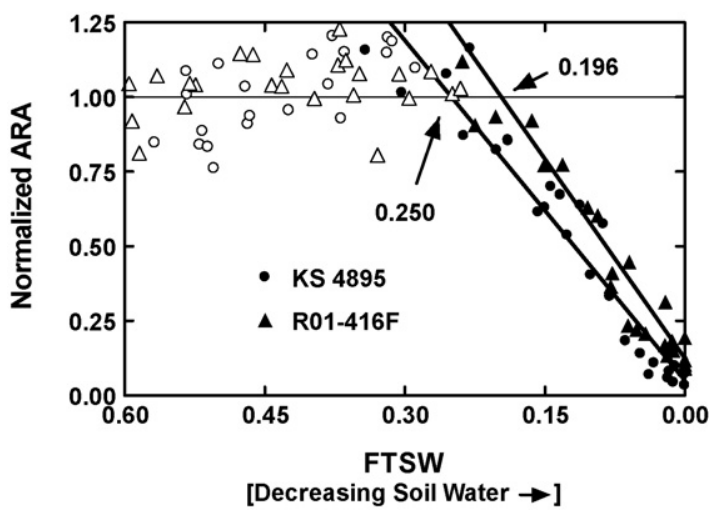

Fig. 4. Greenhouse experiment of daily normalized $\mathrm{N}_{2}$ fixation activity as determined by the acetylene reduction activity (ARA) for individual plants of R01-416F and KS 4895 during a soil drying cycle. The level of soil drying is expressed as the fraction of transpirable soil water (FTSW). The closed symbols represent the subset of data used in the linear regression to estimate the $\mathrm{N}_{2}$ fixation activity when limited by water-deficit stress. The open symbols, which are centered on the normalized ARA value of 1.0, represent the data collected before the occurrence of the decline in ARA as a result of dry soil.

While the field yield results were consistent with a NFDT trait, as were the results from the original greenhouse screening, there was no direct evidence that $\mathrm{N}_{2}$ fixation of these two lines was indeed more tolerant of soil drying. Lines R01-416F, R01$581 \mathrm{~F}$, and other lines were subjected to glasshouse experiments in which NFDT was measured by acetylene reduction during a soil drying cycle. $\mathrm{N}_{2}$ fixation activity of individual plants subjected to soil drying was expressed relative to the $\mathrm{N}_{2}$ fixation activity of well-watered control plants. Both lines showed declines in $\mathrm{N}_{2}$ fixation activity at soil water contents lower than that the soil water content at which $\mathrm{N}_{2}$ fixation activity of the parental line KS 4895 began to decrease. As illustrated in Fig. 4, the decline in $\mathrm{N}_{2}$ fixation activity of KS 4895 was initiated at a soil water content of 0.250 expressed as fraction of transpirable soil water. The decrease in $\mathrm{N}_{2}$ fixation activity was at 0.196 and 0.236 FTSW for R01-416F and R01-581F, respectively. Most importantly, the advantage in $\mathrm{N}_{2}$ fixation activity for the NDFT existed throughout the lower range of FTSW values, which is the zone of soil water content that results in yield loss (Sadras

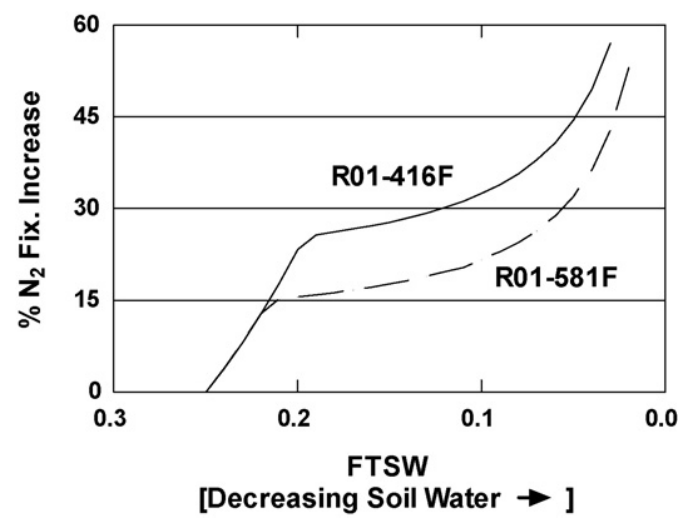

Fig. 5. Graph of $\mathrm{N}_{2}$ fixation activity advantage measured in the zone of soil water deficit for R01-416F and R01-581F relative to the $\mathrm{N}_{2}$ fixation measured for the parental line KS 4895 . and Milroy, 1996). As compared to KS 4895, the $\mathrm{N}_{2}$ fixation activity over much of this range was more than $25 \%$ greater by R01-416F and $15 \%$ greater by R01-581F (Fig. 5). These results are direct evidence of enhanced NFDT in these two lines, supporting the observed yield increases in moderate-yield environments. Also, these results are consistent with the original selection of $\mathrm{R} 01-416 \mathrm{~F}$ and $\mathrm{R} 01-581 \mathrm{~F}$ in the preliminary greenhouse screen.

These two progeny lines with NFDT will be available to public and private breeders for developing superior local cultivars. These genetic resources are expected to result in both increased yields in many current soybean production areas and in expansion of environmental zones where farmers can grow soybean as a key food and feed without the burden of using $\mathrm{N}$ fertilizer.

\section{Acknowledgments}

Yield data were generously provided by Thomas E. Carter, Jr., USDA-ARS, Raleigh, NC, and Ann R. Blount, University of Florida, Quincy, FL. This research was only possible due to the sustained support of U.S. soybean growers through their United Soybean Board.

\section{References}

Boyer, J.S., 1982. Plant productivity and environment. Science 218, 443-448. deSilva, M., Purcell, L.C., King, C.A., 1996. Soybean petiole ureide response to water deficits and decreased transpiration. Crop Sci. 36, 611-616.

Purcell, L.C., deSilva, M., King, C.A., Kim, W.H., 1997. Biomass accumulation and allocation in soybean associated with genotypic differences in tolerance of nitrogen fixation to water deficits. Plant Soil 196, 101-113.

Purcell, L.C., King, C.A., 1996. Drought and nitrogen source effects on nitrogen nutrition, seed growth, and yield in soybean. J. Plant Nutr. 19, 969-993.

Purcell, L.C., King, C.A., Ball, R.A., 2000. Soybean cultivar differences in ureides and the relationship to drought tolerant nitrogen fixation and manganese nutrition. Crop Sci. 40, 1062-1070.

Ray, J.D., Heatherly, L.G., Fritschi, F.B., 2006. Influence of large amounts of nitrogen on nonirrigated and irrigated soybean. Crop Sci. 46, 52-60.

Sadras, V.O., Milroy, S.P., 1996. Soil-water thresholds for the response of leaf expansion and gas exchange: a review. Field Crops Res. 47, 253-266.

Sall, K., Sinclair, T.R., 1991. Soybean genotypic differences in sensitivity of symbiotic nitrogen fixation to soil dehydration. Plant Soil 133, 31-37.

Serraj, R., Sinclair, T.R., 1996a. Processes contributing to $\mathrm{N}_{2}$-fxation insensitivity to drought in the soybean cultivar Jackson. Crop Sci. 36, 961-968.

Serraj, R., Sinclair, T.R., 1996b. Inhibition of nitrogenase activity and nodule oxygen permeability by water deficit. J. Exp. Bot. 47, 1067-1073.

Serraj, R., Sinclair, T.R., 1997. Variation among soybean cultivars in dinitrogen fixation response to drought. Agron. J. 89, 963-969.

Serraj, R., Sinclair, T.R., Purcell, L.C., 1999a. Symbiotic $\mathrm{N}_{2}$ fixation response to drought. J. Exp. Bot. 50, 143-155.

Serraj, R., Vadez, V., Denison, R.F., Sinclair, T.R., 1999b. Involvement of ureides in nitrogen fixation inhibition in soybean. Plant Physiol. 119, 289296.

Sinclair, T.R., 1986. Water and nitrogen limitations in soybean grain production. I. Model development. Field Crops Res. 15, 125-141.

Sinclair, T.R., Serraj, R., 1995. Legume nitrogen fixation and drought. Nature $378,344$.

Vadez, V., Sinclair, T.R., 2002. Sensitivity of $\mathrm{N}_{2}$ fixation traits in soybean cultivar Jackson to manganese. Crop Sci. 42, 791-796.

Vadez, V., Sinclair, T.R., Serraj, R., 2000. Asparagine and ureide accumulation in nodules and shoots as feedback inhibitors of $\mathrm{N}_{2}$ fixation in soybean. Physiol. Plant. 110, 215-223. 